\title{
Correspondence
}

We welcome letters to the Editor concerning articles which have recently been published. Such letters will be subject to the usual stages of selection and editing; where appropriate the authors of the original article will be offered the opportunity to reply.

Letters should normally be under 300 words in length, double-spaced throughout, signed by all authors and fully referenced. The edited version will be returned for approval before publication.

\section{WHICH PRIMARY TOTAL HIP REPLACEMENT?}

Sir,

I read with interest the article in the July 1995 issue by Murray et al entitled 'Which primary total hip replacement?' (1995;77B:520-7). I agree that new-generation implants should be used with caution, in view of the outstanding results of the earlier designs, such as the Charnley.

We have recently carried out a contracting exercise asking interested suppliers to give us a contract price for implants resembling those designed by Charnley. The prices which we were quoted bore no relationship to those listed in the article. This indicates that quoted prices do not always accurately reflect the price which the purchaser pays for the implant.

I also wish to emphasise that a long-term national audit of implant results is long overdue. For some years the Trent Region has been carrying out a region-wide audit of implants under the auspices of Professor Gregg of Leicester. It is not an easy exercise and it will be some time before meaningful results are available. The design of the implant itself is important, but it is not the only factor which will influence the result.

G. W. SIMONDS, MCh(Orth), FRCS

Doncaster Royal \& Montagu Hospital NHS Trust

Doncaster, UK.

Murray DW, Carr AJ, Bulstrode CJ. Which primary total hip replacement? J Bone Joint Surg [Br] 1995;77-B:520-7.

\section{Author's reply:}

Sir,

Mr Simonds makes two important points, both of which have been addressed in our paper. First, manufacturers offer substantial discounts on their implants, but unfortunately, details of these are not readily available. Secondly, a national audit of implants is long overdue. There are plans for one to be started this year.

(C)1996 British Editorial Society of Bone and Joint Surgery

$0301-620 \mathrm{X} / 96 / 31239 \$ 2.00$

J Bone Joint Surg [Br] 1996;78-B:509-11.
We are concerned that $\mathrm{Mr}$ Simond's letter suggests that "implants resembling those by John Charnley" would be as effective as a Charnley implant. These newer implants are all slightly different from the Charnley, as indeed the current Charnley is from the original. These minor modifications may render the prosthesis unsatisfactory.

D. W. MURRAY, MD, FRCS

Nuffield Orthopaedic Centre Oxford, UK.

Sir

I write concerning the paper in the July 1995 issue entitled 'Which primary total hip replacement?' by Murray et al (1995;77-B:5207).

May I congratulate the authors for drawing attention to the important issue of the marketing of prostheses without published documentation. I should like to identify certain practical problems.

First, it is difficult to define what makes a prosthesis 'new'. It would seem impractical to carry out long-term follow-up studies on every prosthesis whenever there was even a minimal modification, but it is difficult to draw a clear distinction between genuinely new prostheses and cosmetic modification. Who knows, in advance, which are which?

The second problem concerns the difficulty of getting the necessary papers published. At the moment, journals of repute which are properly refereed have substantial rejection rates. They do not accept papers unless they are of scientific interest.

Is there an alternative? Perhaps the surgeon with any 'new' prosthesis should himself keep accurate clinical records of all the patients on whom he has used the implant. The results of such a personal follow-up should then be made known to the manufacturer. Another surgeon would then be able to ask the representative of the company which is offering the new prosthesis to supply the information so collected. If this is not forthcoming, it would be foolish for the proposed user to consider using the implant. Obviously, the unsupervised collection of data is not the same as a refereed paper, but it would be for the user to decide whether the author was trustworthy or not.

M. A. R. FREEMAN, MD, FRCS

149 Harley Street

London, UK

Murray DW, Carr AJ, Bulstrode CJ. Which primary total hip replacement? J Bone Joint Surg [Br] 1995;77-B:520-7.

\section{Author's reply:}

Sir,

Mr Freeman identifies some very important points which we, like him, have considered in depth and have been unable to come to any sensible conclusions. What is a 'new' prosthesis? Who would have thought that a minor cosmetic change to the surface finish to the Exeter would have resulted in high failure rates? We believe that all modifications should be viewed with considerable caution.

There is undoubtedly a need for more articles on the results of joint replacement. There is, however, as he points out, a problem with publication. We have suggested that a new journal, perhaps in 
part sponsored by manufacturers, should be considered. Mr Freeman suggests that unpublished data which have not been through any peer-review process are important. We agree with this but it should be treated with caution. There are other possible methods of data acquisition such as registers and trials with standardised patient-based outcome measures, which we have discussed in our paper.

D. W. MURRAY, MD, FRCS

Nuffield Orthopaedic Centre Oxford, UK.

Sir,

Many articles published in the Journal of Bone and Joint Surgery deal with the problems of total hip replacement. Most report good results and this leads to consideration as to whether a consensus has been reached as to the optimum procedure. The article by Murray et al entitled 'Which primary total hip replacement?' in the July 1995 issue (1995;77-B:520-7) is of great interest. In Table I the authors give details of the implants on the market in the UK in 1994, listing more than 60 designs; thus, in spite of the published good results, "many new designs of THR have been introduced in recent years". They quote eight articles which reported a survival rate of more than $95 \%$ after five years, most with a $98 \%$ to $99 \%$ success, but many implants had no published results. The only reference quoted in German was Thabe et al (1993). This study reported a 98\% survival of the Link Ribbed Hip system. Murray et al failed to cite at least two British papers, published in the same issue of the journal by Sweetnam et al and by Savilahty et al, stating that this system gives very poor results.

They list the Bi-contact system as having "no published results", but a study was published in 1993 by Volkmann.

G. KRAKOVITS, MD, CSc

Department of Orthopaedic Surgery and Trauma

János Kórheaz

Budapest, Hungary.

Murray DW, Carr AJ, Bulstrode CJ. Which primary total hip replacement?. J Bone Joint Surg [Br] 1995;77-B:520-7.

Savilahti S, Myllyneva I, Lindholm TS, et al. Clinical outcome and survival of Link RS total hip prosthesis. J Bone Joint Surg [Br] 1995;77B:369-73.

Sweetnam DIS, Lavelle J, Muirhead-Allwood W, Cohen B. Poor results of the ribbed hip system for cementless replacement. J Bone Joint Surg [Br] 1995;77-B:366-8.

Thabe H, Wolfram U, Schill S. Mittelfristige ergebnisse mit der zementfreien Link endoprosthese. Z Orthop 1993;131:568-73.

Volkmann R. The Bicontact endoprosthesis system: intermediate results of five years' use. Aktuelle Traumatol 1993;23 Suppl 1:75-87.

\section{Author's reply:}

Sir,

Dr Krakovits makes two important points which reinforce the comments made in our paper.

First, he emphasises that even if there is one publication suggesting that an implant is satisfactory there may be others which convey the opposite impression. We were unable to include in our study the later papers which he quotes as they were published after our article was accepted for publication. It is therefore essential that more long-term results are published.

Secondly, he states that the Bi-contact system does have a reported outcome (Volkmann 1993). It is always difficult to obtain all the relevant literature for a review; we predominantly obtained references from the manufacturers and distributors.
Since we did not receive this information this suggests that some manufacturers or distributors do not feel that orthopaedic surgeons are very interested in peer-reviewed publications. This can only be because orthopaedic surgeons give that impression.

D. W. MURRAY, MD, FRCS

Nuffield Orthopaedic Centre

Oxford, UK.

Volkmann R. The Bicontact endoprosthesis system: intermediate results of five years' use. Aktuelle Traumatol 1993;23 Suppl 1:75-87.

\section{KNEE PAIN AFTER TIBIAL NAILING}

\section{Sir,}

We read with interest the brief report in the November 1995 issue by Orfaly et al of a retrospective review of 107 patients treated for tibial fracture with a reamed Gross-Kempf nail (1995;77-B:976-7). Knee pain, which is the commonest complication after intramedullary nailing, has been mentioned before by the Edinburgh group (Court-Brown, Christie and McQueen 1990). The importance of minimising this symptom by using a paratendinous approach is emphasised.

We have a number of concerns about this paper. The authors used the symptom of pain as their end-point, ignoring signs such as local tenderness and the inability to kneel. The incidence of knee tenderness is important to the orthopaedic surgeon wishing to provide informed consent for his patients. The inability to kneel for up to a year, and perhaps more, after injury could affect the patient's return to employment.

The paper is a retrospective review and without a control group it cannot be stated that the knee pain is not due to the injury itself. Shortening of the patellar tendon, which is known to occur after surgery to the knee, has been ignored. Another obvious confounding variable, neuroma formation in the scar, has been missed because the clinical signs were not investigated.

A randomised, controlled, prospective study which measured symptoms and signs and all of the confounding variables that are thought to play a part in the pathology of knee pain would answer our concerns.

\section{J. R. W. HARDY, FRCS, FRCS Ed \\ P. J. GREGG, MD, FRCS C. \\ WOOD, BSc, FRSS \\ Glenfield Hospital NHS Trust, \\ Leicester, UK.}

Court-Brown CM, Christie J, McQueen MM. Closed intramedullary tibial nailing. J Bone Joint Surg [Br] 1990;72-B:605-11.

Orfaly R, Keating JF, O'Brien PJ. Knee pain after tibial nailing: does the entry point matter? J Bone Joint Surg [Br] 1995;77-B:976-7.

\section{Author's reply:}

Sir,

The aim of our report was to draw attention to the prevalence of knee pain after tibial nailing and its relationship to the entry point chosen. We agree with the recommendation that this problem is worthy of a detailed prospective study.

Assessment of the length of the patellar tendon poses methodological difficulties since good preoperative lateral radiographs of the injured knee may not be available. The radiological estimation of changes in length would require postoperative lateral radiographs of the contralateral knee taken in a standard fashion to estimate changes in length on the injured side. These were not available to us as part of our retrospective review. 
Four patients in our series had neuritis of the saphenous nerve, possibly due to a neuroma, but this was quite different from the anterior knee pain which we studied and they were not considered in our analysis of the patients with knee pain. The brevity of text required for a brief report did not allow us to discuss these details.

J. F. KEATING, M Phil, FRCS Ed(Orth)

Royal Infirmary of Edinburgh

Edinburgh, UK

Sir,

In their article in the November 1995 issue Entitled 'Knee pain after tibial nailing: does the entry point matter' (1995;77-B:976-7), Orfaly, Keating and O'Brien confirmed that subsequent anterior knee pain was common (56\% of patients) and concluded that a paratendinous approach was less likely to cause this (51\%) than one which split the patellar tendon (78\%). We agree with their findings and routinely use the paratendinous approach (Mulcahy and McElwain 1995).

The incidence of anterior knee pain after nail insertion, however, remains high. We have performed arthroscopy in several knees after tibial nailing. A frequent, but as yet unquantified finding, was the presence of degenerative changes on the under-surface of the patella.

We believe that tibial nail insertion, with the knee flexed, induces considerable retropatellar pressure, since the patella is both subluxed laterally and driven against the femoral surface beneath. We are in the process of confirming this clinical impression in a cadaver model.
Meanwhile, we try to minimise the traction on the tibia during insertion of the nail and to release the patellar tendon from the subluxed position as quickly as possible.

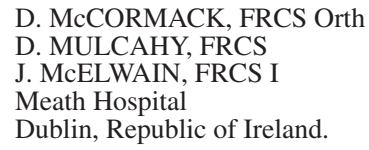

Mulcahy DM, McElwain JP. Grosse-Kempf reamed nailing of tibial fractures. Irish Coll Physcn Surg 1995;24:174-6.

Orfaly R, Keating JF, O'Brien PJ. Knee pain after tibial nailing: does the entry point matter? J Bone Joint Surg [Br 1995;77-B:976-7.

\section{Author's reply:}

Sir,

We agree with McCormack et al that knee pain after tibial nailing is likely to be multifactorial and that the patellar tendon splitting approach is only one contributory cause. We accept that there is a possibility of articular damage to the surface of the patella at the time of nail insertion. Many patients with knee pain after tibial nailing, however, improve after extraction of the nail which points to causes other than degenerative changes at the patellofemoral joint.

J. F. KEATING, MPhil, FRCS Ed(Orth)

Royal Infirmary of Edinburgh

Edinburgh, UK. 